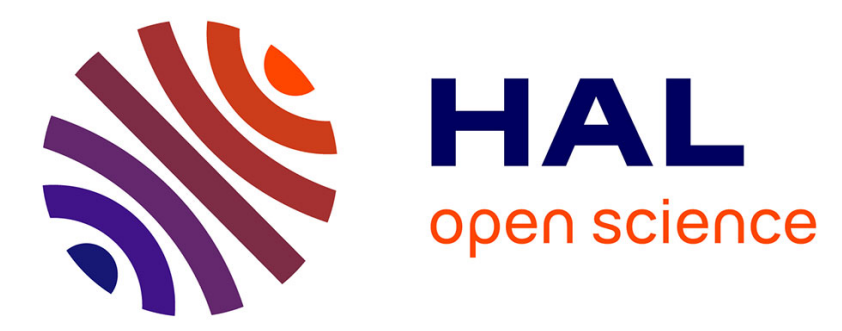

\title{
The Timing of Elections in Federations: A Disciplining Device against Soft Budget Constraints?
}

Karolina Kaiser, Emmanuelle Taugourdeau

\section{To cite this version:}

Karolina Kaiser, Emmanuelle Taugourdeau. The Timing of Elections in Federations: A Disciplining Device against Soft Budget Constraints?. 2010. halshs-00492085

\section{HAL Id: halshs-00492085 https://shs.hal.science/halshs-00492085}

Submitted on 15 Jun 2010

HAL is a multi-disciplinary open access archive for the deposit and dissemination of scientific research documents, whether they are published or not. The documents may come from teaching and research institutions in France or abroad, or from public or private research centers.
L'archive ouverte pluridisciplinaire HAL, est destinée au dépôt et à la diffusion de documents scientifiques de niveau recherche, publiés ou non, émanant des établissements d'enseignement et de recherche français ou étrangers, des laboratoires publics ou privés. 


\section{Documents de Travail du Centre d'Economie de la Sorbonne}
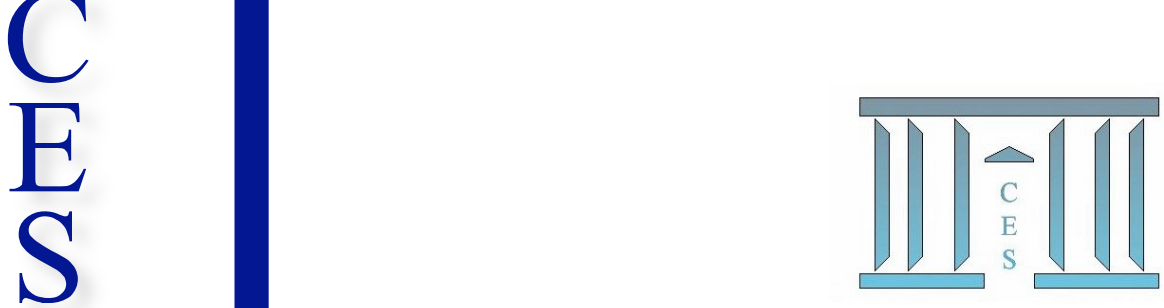

The Timing of Elections in Federations : A Disciplining

Device against Soft Budget Constraints?

Karolina KAISER, Emmanuelle TAUGOURDEAU

2010.36

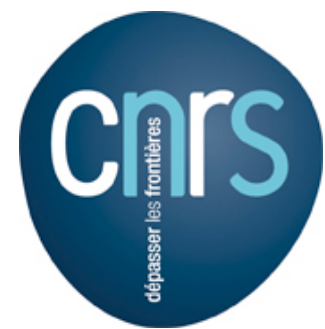

Maison des Sciences Économiques, 106-112 boulevard de L'Hôpital, 75647 Paris Cedex 13 


\section{The Timing of Elections in Federations: A Disciplining Device against Soft Budget Constraints? *}

\author{
Karolina Kaiser $^{\dagger}$ \\ University of Munich
}

\author{
Emmanuelle Taugourdeau ${ }^{\ddagger}$ \\ CNRS, CES, Paris School of Economics
}

February 2010

\author{
February 2010
}

*For valuable comments and suggestions we would like to thank Andreas Haufler, Marie-Laure Breuillé, Basak Akbel, the participants of the 3rd IEB Workshop on Fiscal Federalism in Barcelona, the participants of the Soft Budget Constraint Workshop in Osaka, Japan, as well as the participants of the Research Seminar and the Public Economics Seminar at the Ludwigs-Maximilians-University Munich.

${ }^{\dagger}$ University of Munich, Ludwigstr. 33/III, 80539 Munich, Germany. Tel: +49 8921806781. Email: karolina.kaiser@lrz.uni-muenchen.de

${ }^{\ddagger}$ ENS Cachan, CES, Laplace 309, 61 avenue du president Wilson, 94235 Cachan Cedex, France. Email: emmanuelle.taugourdeau@ens-cachan.fr 


\begin{abstract}
We introduce political economics into the soft budget constraint problem by asking if the timing of elections has the potential to harden budget constraints. Specifically, we ask under which circumstances the soft budget constraint problem is worse - with synchronized elections, i.e. simultaneous central and regional office terms, or with staggered elections, i.e. terms of office that do not coincide. We find that staggered elections clearly improve fiscal discipline at the local level as well as welfare.
\end{abstract}

Keywords: Soft Budget Constraints, Fiscal Federalism, Elections. JEL Classification: D72, H77

\title{
Résumé
}

Dans cet article, nous introduisons des élements d'économie politique dans un problème de contrainte budgétaire molle en étudiant si l'organisation simultanée ou décalée des éléctions nationales et locales a un impact sur la discipline budgétaire des gouvernements locaux. Nous montrons que des élections décalées permettent très clairement de durcir la contrainte budgétaire molle et améliorent le bien-être des agents de la fédération. Ce résultat s'explique par le fait que le gouvernement central bénéfécie d'une position de leadership en élections décalées qui permet de contenir le comportement opportuniste des gouvernements locaux.

Mots-clef: Contrainte Budgétaire Molle, Fédéralisme Fiscal, Elections.

Classification JEL : D72, H77 


\section{Introduction}

Following (Rodden et al. , 2003), the soft budget constraint can be defined as "the situation when an entity (say, a province) can manipulate its access to funds in undesirable ways". Although it is widely acknowledged that soft budget constraints may cause inefficiencies ${ }^{1}$ and should therefore be avoided, they are frequently observed (see Vigneault (2007) for an empirical survey). The recurrent emergence of soft budget constraints illustrates the difficulty of totally avoiding them and highlights the importance of better understanding the institutions which help to harden budget constraints.

To our best knowledge, very few papers have dealt with the characteristics of the political system ${ }^{2}$ although soft budget constraints are undoubtedly the results of interactions between two levels of government. In this context, the nature of the interactions may change depending on the electoral timetable. Since the soft budget constraint problem is a problem of commitment and therefore of timing, it might matter if regional and federal governments were elected at identical voting dates and decided at the same time on their revenues and expenditures for the upcoming term or if voting dates fall at different times. In our paper, we ask the question: does the timing of elections in federations matter for the soft budget constraint problem? In other words, in which system are budget constraints harder, with synchronized or with staggered subnational and national terms of office? In practice, we observe either synchronized (Brazilia, Sweden or Denmark) or staggered (Canada, Germany or Australia) elections ${ }^{3}$ but the topic of concurrent vs. non-concurrent elections has received little attention for economic purposes although it has attracted the interest of political scientists ${ }^{4}$. The arguments in favor of one or the other system are usually based on cost considerations and on the question of voters' confusion/motivation, but economic arguments are often missing in the debate. So, in contrast to the existing literature, we focus not on political but on economic variables such as the size of federal transfers, the amount of taxes raised and the magnitude of public and private consumption.

To answer our question we consider a simple model with $T$ periods. A term of

\footnotetext{
${ }^{1}$ There are exceptions which show that soft budget contraints may diminish inefficiencies arising from hard budget constraints (see Besfamille and Lockwood, 2008).

${ }^{2}$ One exception is Goodspeed (2002) who considers voting in his bailout model by including exogenous re-election probabilities for the central government. However, in contrast to our paper, he does not consider any interaction between the local and national elections.

${ }^{3}$ See Diamond, Larry, and Marc F. Plattner, eds. Electoral Systems and Democracy Baltimore: Johns Hopkins University Press pp 272 for more details.

${ }^{4}$ In particular, the political sciences analysis has investigated how the timing of elections interacts with different political variables such as the emergence of divided governments in presidential systems (Shugart, 1995), accountability of politicians (Samuels, 2004) or voter turnout (Hajnal and Lewis, 2003).
} 
office for both the federal and the local governments lasts for two periods. Local and federal office terms can either be synchronized (SY) or staggered (ST). As a synchronized office term regime we define a model setup where elections and therefore the terms of office for regional and federal governments coincide. On the contrary, a staggered office term setting is a situation where regional elections take place just in the middle of the central government office term. Therefore the terms of office of old and new federal and regional governments overlap. Finally, we consider the situation of one region eligible for a federal discretionary grant on which the central government cannot commit. The federal government is inclined to allocate the grant due to lobbying, log-rolling practises or political purposes. By opposition to the mandatory grants which are rules-based obligations for the central government, discretionary grants are decided on a discretionary basis (some local jurisdictions may benefit from them whereas others not). On the average of the OECD countries, the discretionary grants represent around $20 \%$ of the total amount of grants (Joumard et al. , 2005). In this article, we focus our analysis on the electoral system which diminishes the local incentives to manipulate the access to federal discretionary grants once a region is eligible. Indeed, as it has been observed in Finland where municipalities can apply for discretionary grants that are available during periods of exceptional circumstances, the system has in practice significantly reduced the incentives for fiscal discipline at the municipal level and "exceptional" grants are disbursed on an annual basis (Bergvall et al. , 2006). To reach our objective, we associate elections to a political program or an agenda which is implemented at the beginning of the office term. In other words, policy variables are decided by the governments for the whole term when they enter office.

Interestingly, we find that the staggered office terms clearly dominate the synchronized office terms. The intuition for this finding is that in the staggered term setting the central government obtains a first mover advantage vis-à-vis the regional government entering next. This advantage is not at work for synchronized elections since bailouts are always chosen once all other economic variables are decided. With staggered elections, the first mover advantage enables the federal government to anticipate the strategic behavior of the next regional government, making it relatively easier to limit grants. Budget constraints are hardened by allocating less funds to the second half of the office term and using them to improve the allocation in the first half, where the old regional government can no longer strategically respond to actions of the central government because it has already made its tax and expenditure decisions in the previous period.

Our paper contributes to the literature of soft budget constraints by adding a political economy dimension to the debate. The soft budget constraint concept was introduced by Janos Kornai $(1979,1980)$ in the context of socialist enterprises 
which got losses reimbursed by the state. Thereafter, this concept became perfectly suitable to analyze the consequences of decentralization and more precisely the interactions between several tiers of governments (for a literature overview see Kornai and al. 2003). Soft budget constraints are difficult to avoid and are associated with major incentive problems regarding the accountability of regional governments in terms of fiscal discipline. Therefore one important area of public economic research asked the question: how is the softness of budget constraints affected by different characteristics of federations such as the size of regions (Wildasin, 1997 and Crivelli \& Staal, 2006), the type of fiscal equalization system or the intensity of tax competition (Qian and Roland, 1998 and Breuillé and al, 2006 , Koethenbuerger, 2007)? We go further along these lines by introducing political economic arguments generally developed in political science.

The remainder of the paper is organized as follows. Section 2 presents the basic model setup and Section 3 introduces a benchmark case, where a social planner makes efficient taxation and expenditure decisions. In Section 4 we introduce a decentralized setup, where regional governments decide on regional taxation and expenditures and the central government is responsible for national public good provision. In addition, the central government has the opportunity to supplement regional public good provision through a bailout. In Section 4.1 we analyze synchronized terms of office (SY) and in Section 4.2 staggered terms of office (ST). Welfare is analyzed in Section 5 and Section 6 concludes.

\section{Model}

We consider a model of a federation with one region eligible for a discretionary grant and several regions which are not eligible for a grant ${ }^{5}$. The population of the eligible region is normalized to one, and the population of the non-eligible regions is normalized to $N, N>0$, such that we have a total population of $(N+1)$.

Consumers At each date $t$, consumers in each region have an initial endowment of $w$ and derive utility from a private good $c_{t}$, a regional public good $g_{t}$ and a national public good $G_{t}$. The payoffs of consumers at a given date $t$ are modeled according to a log-linear utility function: $c_{t}+\gamma_{g} \ln g_{t}+\gamma_{G} \ln G_{t}$.

Governments Governments are assumed to hold political power for one term of office, which is divided into two sub-periods, the "post-electoral period" and the "pre-electoral period".

\footnotetext{
${ }^{5}$ We may assume that a proportion of the regions is eligible for a grant, but for symmetric eligible regions, it would not modify the results. To make the analysis clearer, we concentrate on the case of one eligible region.
} 
Regional Governments At the beginning of each office term, regional governments choose their tax and expenditure policy. We act on the assumption that regional governments, when entering office, fix their tax and expenditure policies in a political program that is valid for the whole office term. In that sense, we consider that governments do not deviate from their agenda over time. This assumption enables us to link the elections to a political program and to concentrate our analysis on the timing of elections (staggered versus simultaneous). For reasons of simplicity, we abstract from distortionary taxation and allow regional governments to choose a regional lump sum $\operatorname{tax} \tau_{t}^{R}$ as a revenue raising instrument. The revenue collected can either be used for expenditures in the post-electoral period $\left(s_{t}\right)$ or in the pre-electoral period $\left(s_{t+1}\right)$. At the end of the term, the budget has to be balanced: $\tau_{t}^{R}=s_{t}+s_{t+1}$. While for non-eligible regions, regional public consumption $g_{t}$ is solely financed by regional spending, the eligible region might in addition receive a grant $z_{t}>0$ as a subsidy to regional expenditures, such that the regional budget constraint is represented by $g_{t}=s_{t}+z_{t}, \forall t$. The payoff of a regional official in one office term is represented by the following utility function:

$$
c_{t}+\gamma_{g} \ln g_{t}+\gamma_{G} \ln G_{t}+c_{t+1}+\gamma_{g} \ln g_{t+1}+\gamma_{G} \ln G_{t+1}
$$

The separability of utility from regional, national and private consumption along with the quasi linearity assumption implies that optimal tax choices of the non-eligible regions are completely independent from tax choices of the eligible region.

Central government The central government has an own non-manipulable head tax $\tau_{t}^{C}$, which is financed from the initial endowment $w$ of consumers and is collected at the beginning of the central government's office term from each resident of the federation. The fixed level of the federal lump sum tax may be criticizable, but it enables us to concentrate our analysis on the local government behavior, which is the aim of the soft budget constraint analysis ${ }^{6}$. The total revenue $(1+N) \tau_{t}^{C}$ can be used for post-electoral central government spending $S_{t}$ or pre-electoral spending $S_{t+1}$. In addition, in each period the central government has to decide how to split up total spending among the national public good $G_{t}$ and a grant to the eligible region $z_{t}$. Although particular grant programs may be temporary, we argue that discretionary grants in general are given on a permanent basis to an eligible region. The central government has to balance the budget over the whole term, i.e. $(1+N) \tau_{t}^{C}=S_{t}+S_{t+1}$, as well as in each period, i.e. $S_{t}=G_{t}+z_{t}, \forall t$.

\footnotetext{
${ }^{6}$ It is possible to show that our results persist even with endogenous central government taxation.
} 
In order to make the problem interesting, we have to make a technical assumption regarding the exogenously given central government head tax. We assume that the revenue collected from the head tax is, on the one hand, large enough that a soft budget problem arises, and on the other hand, small enough that it is not possible that all activity of the eligible region is fully financed by central government grants in all periods, i.e. $g_{t}+g_{t+1}<z_{t}+z_{t+1}$ and $z_{t}>0, \forall t$. This assumption is technically necessary to obtain an interior solution for the soft budget problem and to avoid corner solutions. The central government objective function is defined as:

$$
c_{t}+\gamma_{g} \ln g_{t}+(1+N) \gamma_{G} \ln G_{t}+c_{t+1}+\gamma_{g} \ln g_{t+1}+(1+N) \gamma_{G} \ln G_{t+1}
$$

Since private and regional consumptions of the non-eligible regions are independent of the central government's actions, they are disregarded in the central government's objective function. However, this does not hold for the utility from the national public good, which is considered for all $(1+N)$ inhabitants.

Timing In the synchronized office terms set-up, we face an infinitely repeated game, where at each date $t+2 n, n \in \mathbb{Z}$ both a central and a regional government enter and stay for one office term, consisting of a post-electoral and a pre-electoral period. In the staggered office terms set-up there exists also an infinitely repeated game, where at each date $t+2 n, n \in \mathbb{Z}$ a central government and at each date $(t+1)+2 n, n \in \mathbb{Z}$ a regional government enter. Regional and central governments decide when coming into office on the intertemporal distribution of spending, i.e. $s_{t}, s_{t+1}$ and $S_{t}$, the level of $\tau^{R}$ and $S_{t+1}$ being derived directly from the choices of $s_{t}, s_{t+1}$ and $S_{t}$. The grants $z_{t}$ are chosen ex-post at each date $t$, after all other fiscal decisions have been made. The timing of each set-up is explained in more detail in the corresponding sections.

Before we move on to the construction of the synchronized and the staggered terms of office regimes, we first establish a benchmark case, where a social planner maximizes the utility of all inhabitants over the whole office term.

\section{Social Planner}

The social planner program serves as an efficiency benchmark. The social planner solves the following problem, 
$\max _{s_{t}, s_{t+1}, z_{t}, z_{t+1}, S_{t}} c_{t}+\gamma_{g} \ln g_{t}+(1+N) \gamma_{G} \ln G_{t}+\left(c_{t+1}+\gamma_{g} \ln g_{t+1}+(1+N) \gamma_{G} \ln G_{t+1}\right)$

subject to the budget constraints:

$$
\begin{aligned}
c_{t} & =w-\tau_{t}^{R}-\tau^{C} \quad c_{t+1}=w \\
g_{t} & =s_{t}+z_{t} \quad g_{t+1}=s_{t+1}+z_{t+1} \\
G_{t} & =S_{t}-z_{t} \quad G_{t+1}=S_{t+1}-z_{t+1}
\end{aligned}
$$

and the budget balancing constraints:

$$
\tau_{t}^{R}=s_{t}+s_{t+1} \quad(1+N) \tau^{C}=S_{t}+S_{t+1}
$$

From the first order conditions w.r.t. $s_{t}, s_{t+1}, z_{t}, z_{t+1}$ we obtain a unique solution for regional public consumption $g_{t}=g_{t+1}=\gamma_{g}$, for national public consumption: $G_{t}=G_{t+1}=(1+N) \gamma_{G}$, for the regional tax rate $\tau_{t}^{R}=2\left(\gamma_{g}+(1+N) \gamma_{G}\right)-$ $(1+N) \tau^{C}$ and for private consumption $c_{t}=w-2\left(\gamma_{g}+(1+N) \gamma_{G}\right)+N \tau^{C}$, $c_{t+1}=w$. Through the budget balancing constraint $\tau_{t}^{R}=s_{t}+s_{t+1}$ the sum of optimal regional spending is determined. However, the social planner is indifferent between spending the given regional tax revenue in period $t$ or in period $t+1$, because grants $z_{t}$ constitute a second instrument which allows the provision of an optimal level of regional goods for each given level of spending $0 \leq s_{t} \leq \tau_{t}^{R}$.

The sum of grants over both office periods $\left(z_{t}+z_{t+1}\right)$ equals $(1+N)\left(\tau^{C}-2 \gamma_{G}\right)$. Because the social planner accounts for all externalities associated with the grants, this level of grants represents the ex-ante efficient amount. If the central government could commit, it would pay this amount no matter what tax rate the eligible region chooses. However, in the subsequent set-ups we analyze a situation where the central government cannot commit to an efficient level of grants and tax policy is decentralized. In a simple one period model, these assumptions would lead to an inefficiently low regional tax rate and to inefficiently high grants for the eligible region. The intuition for this result is that the eligible region fails to account for the negative externalities associated with the grants. In the following section, we ask if this result persists in the same fashion for different office term regimes (i.e. modified timings). 


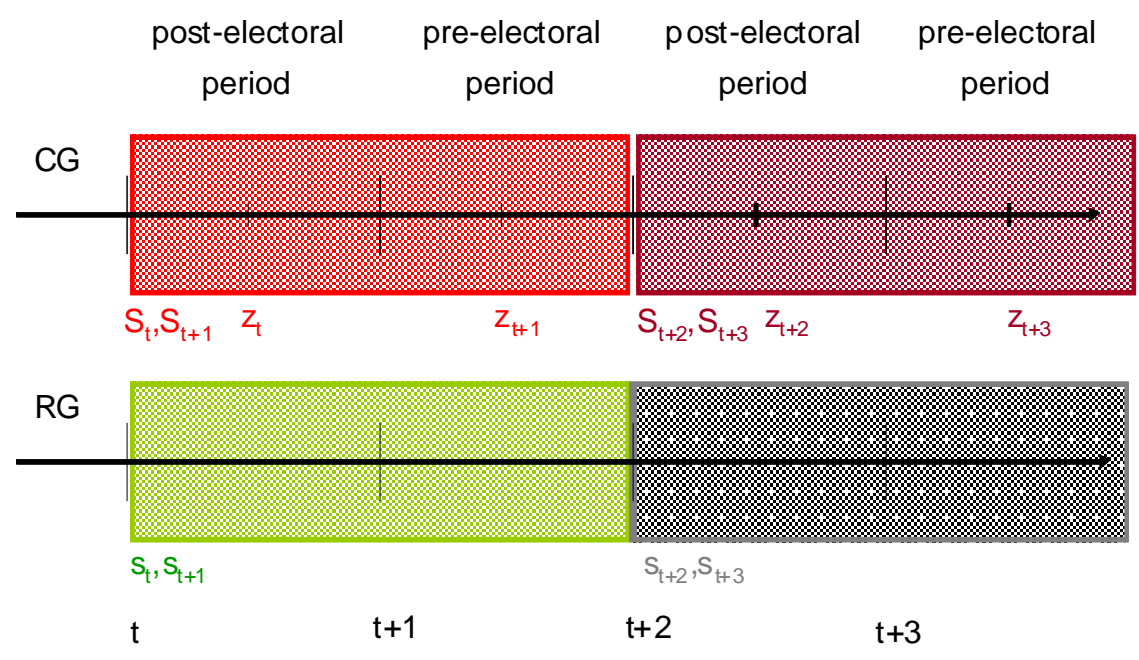

Figure 1: Timing in the SY Regime

\section{Decentralized Setup}

In this section we introduce a decentralized set-up where regional governments choose the regional tax rate as well as regional expenditures whereas the central government chooses both the level of national expenditures and the amount of grants allocated to the eligible region.

\subsection{Synchronized Office Terms}

In the synchronized set-up, both a new regional and a new federal government enter into office at the beginning of each term, and decide simultaneously on their expenditure policy. Additionally, at the end of each period, the central government decides on the level of grants. This sequence of events is repeated infinitely ${ }^{7}$. Given that new officials enter at the beginning of each term, there are no strategic interactions across terms, and it is therefore sufficient to solve the game for one office term.

The basic structure of this game is identical to a standard two-stage game with decentralized leadership of the regional government, which can be solved by backward induction.

${ }^{7}$ The ex-post grant yields an identical outcome as if an ex-ante efficient grant is calculated which is topped up ex-post to an inefficiently high amount. 
At stage 2, the central government maximizes its objective function (2) w.r.t. $z_{t}$ and $z_{t+1}$ subject to the budget constraints $(4)-(7)$. The solution of this problem is the following grant scheme:

$$
z_{t}=\frac{\gamma_{g} S_{t}-(1+N) \gamma_{G} s_{t}}{(1+N) \gamma_{G}+\gamma_{g}} \quad \forall t
$$

The central government is restricted in its actions in the sense that it is just allowed to increase regional revenue through grants, but not to reduce it, i.e. $z_{t} \geq 0$. Therefore the solution is an interior solution to a Kuhn-Tucker problem. The grant function illustrates as well that the regional budget constraint is soft in the sense that it is optimal for the central government to compensate a reduced regional government spending with an increase of grants $\frac{d z_{t}}{d s_{t}}<0$. The transfer is chosen such that the preferences of the central government on the distribution of public funds across the regional and the national public good are realized. As it is typical for Cobb-Douglas type utility functions, for each type of public good a constant share of revenue is spent. This becomes obvious when the grant (8) is plugged into regional and national public consumption: $g_{t}=\frac{\gamma_{g}}{(1+N) \gamma_{G}+\gamma_{g}}\left(S_{t}+s_{t}\right)$ and $G_{t}=\frac{(1+N) \gamma_{G}}{(1+N) \gamma_{G}+\gamma_{g}}\left(S_{t}+s_{t}\right)$.

At stage 1, a Nash game between the central and the regional government is played when deciding on the expenditure policy for the following term of office. While the regional government maximizes the utility of its own residents when maximizing (1) w.r.t. $s_{t}$ and $s_{t+1}$, the central government cares for the utility of all $(1+N)$ residents by maximizing (2) w.r.t. $S_{t}$ (and $S_{t+1}$ via the budget balancing constraint (7)), subject to all budget constraints. We obtain the following response functions for the central and the regional governments:

$$
\begin{aligned}
S_{t} & =\frac{\left(s_{t+1}-s_{t}\right)+(1+N) \tau^{C}}{2} \\
s_{t}+s_{t+1} & =\left(\gamma_{g}+\gamma_{G}\right) 2-(1+N) \tau^{C}
\end{aligned}
$$

The best response function of the central government (9) shows the intertemporal preferences of the central government. The adjustment of $S_{t}$ according to (9) insures that a constant fraction of funds is spent in the post-electoral period and in the pre-electoral period for each combination of $s_{t}$ and $s_{t+1}$ chosen by the regional government.

While the regional government's best response function (10) is sensitive to the sum of central government spending $S_{t}+S_{t+1}=(1+N) \tau^{C}$, it is insensitive to the intertemporal distribution of central government funds, i.e. to $S_{t}$.

The intuition for the results can be summarized as a 'distribution effect' 
and a 'level effect'. The distribution effect implies that the central government is decisive when it comes to the distribution of public funds through the stage 2 reaction function (8) as well as the stage 1 best response function (9). For the distribution of a given amount of funds between the regional and the national public good this is true because the central government has the final decision power by allocating grants ex-post ${ }^{8}$. However, the regional government is decisive with respect to the level effect, i.e. for the level of total funds available for public consumption. This follows directly from the assumption that the central government has an exogenously given amount of tax revenue which it cannot manipulate. The regional government clearly prefers a lower amount of spending than the central government would do if it could choose the regional lump sum tax. By reducing its tax rate, the regional government benefits because it receives in turn grants whose costs are borne by all the residents of the federation. This negative interregional externality of the grant is characterized by a decrease of utility from national public consumption by the $N$ outsiders, which the region does not take into account.

Solving for consumption variables yields the following results for private and public consumption:

$$
\begin{gathered}
c_{t}=w+N \tau^{C}-2\left(\gamma_{g}+\gamma_{G}\right) \\
c_{t+1}=\gamma_{g} \frac{\gamma_{g}+\gamma_{G}}{\gamma_{g}+(1+N) \gamma_{G}} \quad g_{t+1}=\gamma_{g} \frac{\gamma_{g}+\gamma_{G}}{\gamma_{g}+(1+N) \gamma_{G}} \\
G_{t}=(1+N) \gamma_{G} \frac{\gamma_{g}+\gamma_{G}}{\gamma_{g}+(1+N) \gamma_{G}} \quad G_{t+1}=(1+N) \gamma_{G} \frac{\gamma_{g}+\gamma_{G}}{\gamma_{g}+(1+N) \gamma_{G}}
\end{gathered}
$$

If there were no residents outside the eligible region $(N=0), \frac{\gamma_{g}+\gamma_{G}}{\gamma_{g}+(1+N) \gamma_{G}}$ would equal one and the preferences of the regional and the central governments would coincide with the social planner's choices. $N>0$ introduces interregional externalities that let the regional and national public goods be underprovided since the negative externalities of raising too little revenue are not taken into account by the regional government. The following proposition summarizes the implications for the level of grants.

Proposition 1 A decentralized leadership with synchronized office terms is associated with a higher level of grants than the social planner set-up.

\footnotetext{
${ }^{8}$ Note that there is no conflict of interest between the central and the regional governments on the intertemporal distribution of revenue because both governments prefer half of the funds in period $t$ and half of the funds in period $t+1$.
} 
Proof. In the social planner solution we have:

$$
\left(z_{t}+z_{t+1}\right)^{S P}=(1+N)\left(\tau^{C}-2 \gamma_{G}\right)
$$

whereas for the synchronized terms of office solution of the decentralized leadership we obtain:

$$
\left(z_{t}+z_{t+1}\right)^{S Y}=(1+N)\left(\tau^{C}-2 \gamma_{G} \frac{\left(\gamma_{g}+\gamma_{G}\right)}{(1+N) \gamma_{G}+\gamma_{g}}\right)
$$

and clearly

$$
\left(z_{t}+z_{t+1}\right)^{S P}<\left(z_{t}+z_{t+1}\right)^{S Y}
$$

This result is in line with the existing literature (e.g Goodspeed (2002), Wildasin (1997)) and shows that the decentralized leadership, along with a lack of commitment of the federal government when deciding on the level of grants, creates a soft budget constraint mechanism (equa (8)).

\subsection{Staggered Office Terms}

The staggered office terms set-up characterizes a federation with decentralized regional spending and taxation, where at each date $t+2 n, n \in \mathbb{Z}$ a new central government enters office and at each date $(t+1)+2 n, n \in \mathbb{Z}$ new regional governments come into office. So, it differs from the synchronized elections game by the feature that regional and central election dates do not coincide, but fall on different dates (see Figure 2). This has, first of all, implications for the sequence of events and outcomes.

The central government entering office at date $t$ has to take the regional spending decision $s_{t}$ as given because it has been chosen at date $(t-1)$. So, the central government's position in the post-electoral period becomes weaker in the sense that its spending decision is no longer set simultaneously with the regional government. Instead, the regional government now obtains a first mover advantage. In contrast, the position of the central government at date $(t+1)$ is strengthened vis-à-vis the regional government as it can choose spending in the pre-electoral period $S_{t+1}$ before the regional government chooses $s_{t+1}$. Similarly, the position of the regional government in its post-electoral period is weakened and in its pre-electoral period strengthened. How does this affect outcomes?

We solve this game by backward induction. Given that grants are always allocated ex-post after all other spending decisions have been made, the optimal grant scheme is identical to the grant scheme in the synchronized set-up (8). Once the grant scheme $z_{t}\left(s_{t}, S_{t}\right), \forall t$ is determined, it can be plugged into the public 


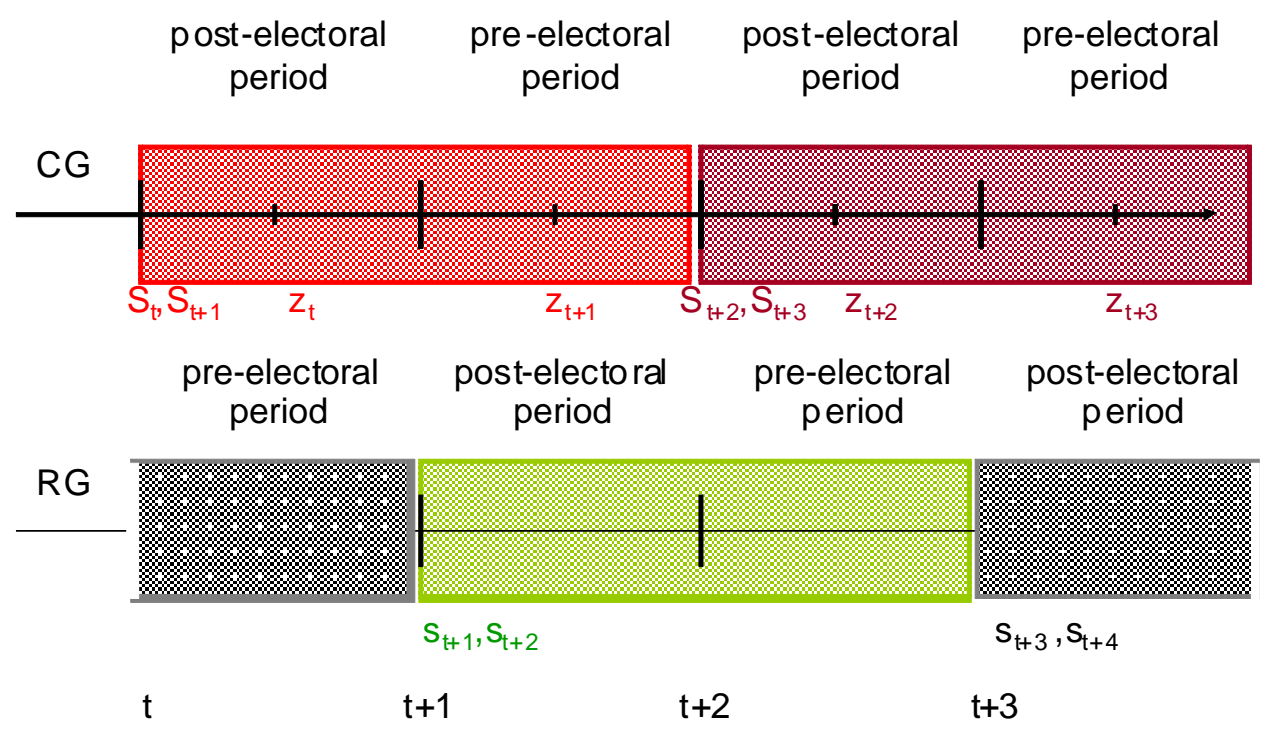

Figure 2: Timing in the ST regime.

consumption variables at all dates and the problem of the synchronized elections set up reduces to the choice of optimal spending for all dates. Although the maximization problems of both governments remain the same, the budget constraints for private consumption (4) and the balanced budget constraint (7) change to:

$$
\begin{array}{cc}
c_{t}=w-\tau^{C} & c_{t+1}=w-\tau_{t+1}^{R} \\
\tau_{t+1}^{R}=s_{t+1}+s_{t+2} & (1+N) \tau^{C}=S_{t}+S_{t+1}
\end{array}
$$

This holds for all dates $t+2 n, n \in \mathbb{Z}$ and $(t+1)+2 n, n \in \mathbb{Z}$ respectively. The other budget constraints stay unchanged.

We start with the calculation of the reaction functions of the regional governments. The quasilinear structure of the utility function makes regional spending decisions for the post-electoral period, e.g. $s_{t+1}$ and the pre-electoral period, e.g. $s_{t+2}$ independent from each other. While $s_{t+1}$ depends only on $S_{t+1}$ (chosen by the central government which entered at date $t$ ), the choice of $s_{t+2}$ depends on the anticipated behavior of the central government entering in the following period $t+2$. Therefore, we determine in a first step the choice of $s_{t+1}$, then we determine central government responses $\frac{\partial S_{t+2}}{\partial s_{t+2}}$ and in a third step, we solve for $s_{t+2}$.

When choosing $s_{t+1}$, the regional government maximizes the objective function:

$$
c_{t+1}+\gamma_{g} \ln g_{t+1}+\gamma_{G} \ln G_{t+1}+\left(c_{t+2}+\gamma_{g} \ln g_{t+2}+\gamma_{G} \ln G_{t+2}\right)
$$


with respect to $s_{t+1}$ taking into account the grant scheme (8) and the budget constraints $(4 a),(5),(7)$ and $(7 a)$. We obtain the following first order condition:

$\frac{\gamma_{g}}{g_{t+1}} \frac{\partial g_{t+1}}{\partial s_{t+1}}+\frac{\gamma_{G}}{G_{t+1}} \frac{\partial G_{t+1}}{\partial s_{t+1}}=1 \quad$ where $\quad \frac{\gamma_{g}}{g_{t+1}} \frac{\partial g_{t+1}}{\partial s_{t+1}}+\frac{\gamma_{G}}{G_{t+1}} \frac{\partial G_{t+1}}{\partial s_{t+1}}=\frac{\gamma_{g}+\gamma_{G}}{S_{t+1}+s_{t+1}}$

The left hand side shows the marginal benefits of an increase in post-electoral spending, taking the responses $\frac{\partial z_{t+1}}{\partial s_{t+1}}$ into account, whereas the right hand side shows the marginal costs, which are constantly one due to the quasilinear consumption. Like in the synchronized elections setting, the regional government disregards the costs of forgone national public good consumption for the $N$ citizens outside its territory. The response function derived from (12) $: s_{t+1}=\left(\gamma_{g}+\gamma_{G}\right)-S_{t+1}$ illustrates that all attempts of the central government to increase public funds in period $t+1$ are counteracted by a reduction of $s_{t+1}$.

Having obtained this response function, we can move on to solve the central government problem at date $t$, which is equal to maximizing (2) w.r.t. $S_{t}$, taking into account response functions (8), (12) as well as the budget constraints $(4 a),(5),(7)$ and $(7 a)$. The solution to this problem is characterized by the first order condition for $S_{t}$ :

$$
\frac{(1+N) \gamma_{G}}{G_{t}}=1 \quad \text { with } G_{t}=\frac{\left(S_{t}+s_{t}\right)(1+N) \gamma_{G}}{\left(\gamma_{g}+(1+N) \gamma_{G}\right)} \quad \forall t+2 n, n \in \mathbb{Z}
$$

The LHS of the condition represents the marginal benefit of an increase of $S_{t}$ which equals the marginal benefit of public consumption (the benefits of regional and national public consumption are equalized through the grant scheme). The RHS represents the marginal costs, which are equal to one. This results from the intertemporal link between $S_{t}$ and $S_{t+1}$ through the balanced budget constraint and the response behavior of the regional government $\frac{\partial s_{t+1}}{\partial S_{t+1}}=-1$ according to (12). Rearranging (13) to the explicit response function $S_{t}=\left(\gamma_{g}+(1+N) \gamma_{G}\right)-s_{t}$ makes it obvious that any attempt of the regional government to increase public funds for period $t$ is fully counteracted by the central government through a decrease of $S_{t}$. The reaction functions (12) and (13) imply that the government entering office in a given period is decisive for the amount of public funds available in this period.

The central government response function (13) enables us to solve as a final step, the regional maximization problem w.r.t. $s_{t+2}$. The marginal costs of raising $s_{t+2}$ are constantly equal to one, because of the quasilinear utility structure. However, the benefits are zero because from the central government response function 
(13) it follows that $\frac{\partial g_{t+2}}{\partial s_{t+2}}=0$ as well as $\frac{\partial G_{t+2}}{\partial s_{t+2}}=0$. Therefore it is optimal for the region to not spend any funds in its pre-electoral period $\left(s_{t+2}=0\right)$.

Solving for consumption variables yields the following results:

$$
\begin{gathered}
c_{t}=w-\tau^{C} \quad w-\left(2\left(\gamma_{g}+\gamma_{G}\right)+N+\gamma_{G}-(1+N) \tau^{C}\right) \\
g_{t}=\gamma_{g} \quad g_{t+1}=\frac{\left(\gamma_{g}+\gamma_{G}\right) \gamma_{g}}{\gamma_{g}+(1+N) \gamma_{G}} \\
G_{t}=(1+N) \gamma_{G} \quad G_{t+1}=\frac{\left(\gamma_{g}+\gamma_{G}\right)(1+N) \gamma_{G}}{\gamma_{g}+(1+N) \gamma_{G}}
\end{gathered}
$$

Intuitively our findings can be explained as follows.

In periods where the central government enters, e.g. in period $t$, the central government has a weak commitment position as it moves second vis-à-vis the regional government. The latter is therefore inclined to a strong moral hazard behavior which is illustrated by zero own contributions to regional public consumption, i.e. $s_{t}=0$. This result seems to be extreme given that the sequence of events is similar to the synchronized office term set-up, where $s_{t}$ is set first and $z_{t}$ afterwards. The reason is that in addition to the interregional externality, an 'intertemporal externality' is in place. This externality becomes effective via the central government budget balancing constraint which decreases the spending in period $t+1$ if period $t$ spending $S_{t}$ increases. However, the regional government deciding at date $(t-1)$ on the level of $s_{t}$ is no longer in office at date $t+1$ and does not consider the costs of reduced public consumption in period $t+1$.

Faced with a situation of zero regional spending, what is the optimal level of central government spending at date $t$ ? Since the regional government has made all decisions for period $t$ at date $(t-1)$ it can no longer respond strategically to the central government's date $t$ choices. However, having obtained a partial first mover advantage, the central government can anticipate the strategic behavior of the regional government entering next via the regional government response function $d(s t+1) / d(S t+1)=-1$. Given that the regional government prefers a lower level of public good provision than the central government, because of the inefficiencies arising from interregional externalities, it is optimal for the regional government to set off each attempt of the central government to shift additional funds in its second office period by reducing regional revenues. This in turn renders it optimal for the central government to spend additional public funds in its first office period and to finance public consumption up to the first best level, where marginal benefits equal marginal costs. This choice entails that period $t$ central government spending increases in period $t$ and decreases in period $(t+1)$ by the 


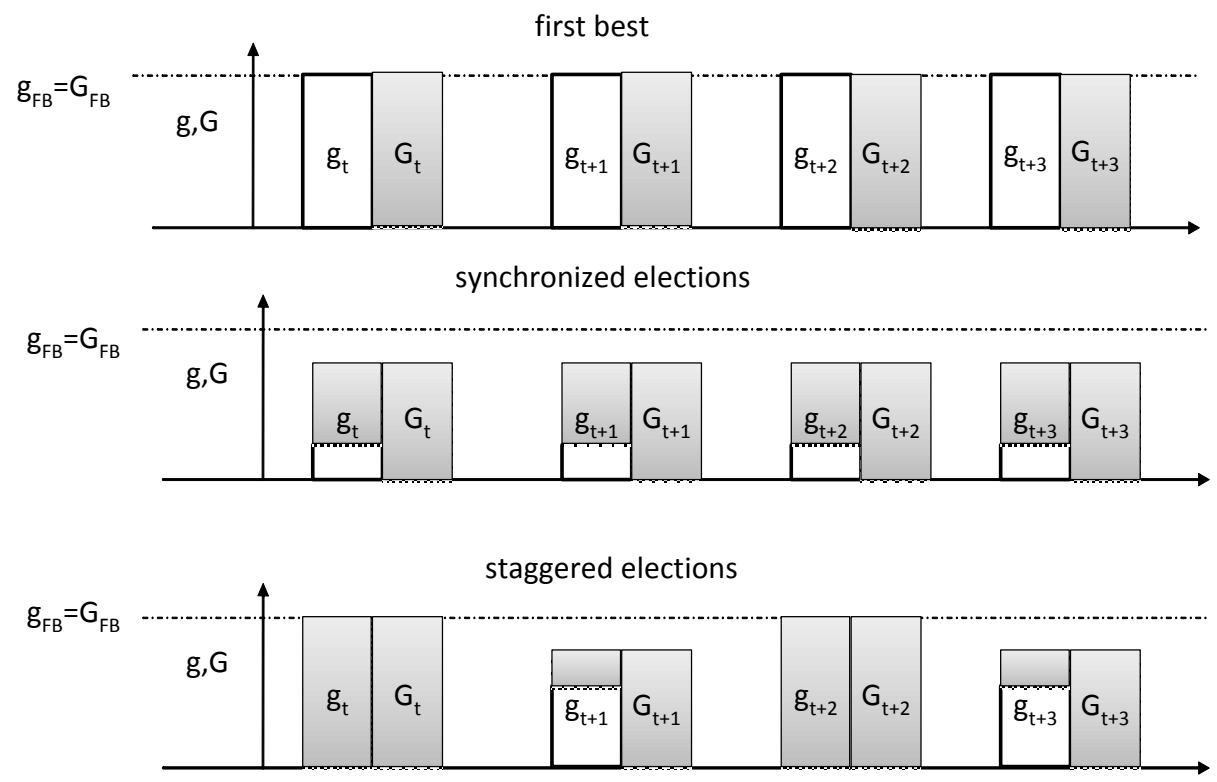

Figure 3: Comparison of FB, SY and ST Results

difference of $\left(\gamma_{g}+(1+N) \gamma_{G}\right)-\frac{\gamma_{g}+\gamma_{G}}{\gamma_{g}+(1+N) \gamma_{G}}\left(\gamma_{g}+(1+N)\right) \gamma_{G}$ that characterizes the difference between the first best and the synchronized elections setup. As a result, the regional government entering at period $(t+1)$ is forced to finance this differential amount by itself. Since the central government's funds are fixed, the additional funds raised by the regional government increase the welfare of the staggered regime above the welfare in the synchronized regime.

Figure 3 illustrates this result and summarizes the differences between the staggered and the synchronized election regimes. For expositional convenience, we assume in our figure that the first best levels of regional and national public good provision are equal. The financing share of the regional government is highlighted in white and the financing share of the central government is highlighted in grey.

The lower graph illustrates the result of the staggered regime. On the one hand, the zero financing contribution of regional governments in periods where the central government enters illustrates how regional governments exploit their first mover advantage. On the other hand, the high contribution share of regional governments in periods when they enter illustrates the power of the central government to enforce a higher overall regional financing contribution in the staggered regime.

We can summarize that in every second period $(t+2 n, n \in \mathbb{Z})$ public consumption coincides with the social planner outcome and in every other period $(t+1+2 n, n \in \mathbb{Z})$ it coincides with the synchronized elections outcome. 
We are now able to make a statement on how the timing of elections affects the softness of budget constraints:

Proposition 2 A decentralized leadership with staggered office terms is associated with a higher level of grants than the social planner set-up, but with a lower level of grants than the synchronized elections set-up.

Proof. In the social planner solution we have:

$$
\left(z_{t}+z_{t+1}\right)^{S P}=(1+N)\left(\tau^{C}-2 \gamma_{G}\right)
$$

whereas for the synchronized office terms solution we obtain:

$$
\left(z_{t}+z_{t+1}\right)^{S Y}=(1+N)\left(\tau^{C}-2 \gamma_{G} \frac{\left(\gamma_{g}+\gamma_{G}\right)}{(1+N) \gamma_{G}+\gamma_{g}}\right)
$$

and for the staggered office terms solution grants are given by:

$$
\left(z_{t}+z_{t+1}\right)^{S T}=(1+N)\left(\tau^{C}-2 \gamma_{G} \frac{\left(\gamma_{g}+\gamma_{G}+\frac{N}{2} \gamma_{G}\right)}{(1+N) \gamma_{G}+\gamma_{g}}\right)
$$

which implies

$$
\left(z_{t}+z_{t+1}\right)^{S P}<\left(z_{t}+z_{t+1}\right)^{S T}<\left(z_{t}+z_{t+1}\right)^{S Y}
$$

Staggered elections serve as a discipline device for the regional governments because the central government benefits more than the regional governments from its partial leadership position.

\section{Welfare Analysis}

Due to the results obtained in the previous sections, we are able to unambiguously rank the welfare of the synchronized and staggered office term regimes.

Proposition 3 The staggered office term regime clearly dominates the synchronized office term regime and we have the following ranking between outcomes:

$$
\begin{array}{rlr}
\tau^{R, S P} & >\tau^{R, S T}>\tau^{R, S Y} \\
g_{t}^{S P} & =g_{t}^{S T}>g_{t}^{S Y} & g_{t+1}^{S P}>g_{t+1}^{S T}=g_{t+1}^{S Y} \\
G_{t}^{S P} & =G_{t}^{S T}>G_{t}^{S Y} & G_{t+1}^{S P}>G_{t+1}^{S T}=G_{t+1}^{S Y}
\end{array}
$$


Proof. See Appendix 1

We drop in this section the time index for the regional tax rate because the same tax rate is set in infinite repetition.

The staggered terms of office outcome coincides in periods where regional governments enter office with the synchronized office terms outcome and in periods where the central government enters with the social planner outcome. Given that the staggered office terms regime is efficient half of the time and inefficient half of the time, while the synchronized office terms regime is inefficient all of the time, the staggered office terms regime clearly dominates.

\section{Discussion}

\subsection{Relaxation of the one-term-of-office assumption}

One critical assumption of our setup is that governments may stay only for one term of office. In this section, we discuss the relaxation of this assumption. Consider a game where each government stays in office for two terms of office, i.e. four periods. Governments enter at date $t$ in the simultaneous regime whereas the regional government enters at date $(t+1)$ in the staggered regime. Hence, both governments care for periods $t$ to $(t+1)$ in the synchronized regime, and in the staggered regime the central government considers the utility of the periods $t$ to $(t+3)$ while the regional government considers $(t+1)$ to $(t+4)$, etc. Solving this game by an identical approach as described in the previous sections yields the result illustrated in figure 4 below, given that governments could commit for all expected office periods.

There is no reason for a change of the result in the synchronized regime, because both the regional and the central government have an equal valuation of utility for all periods, and the effect of the interregional externality remains the same. Similarly, in the staggered elections setup, the central government still has an incentive to bind itself for all periods following period $t$ to force future regional governments to finance, compared to the SY regime, the additional difference of $\left(\left(\gamma_{g}+(1+N) \gamma_{G}\right)-\frac{\gamma_{g}+\gamma_{G}}{\gamma_{g}+(1+N) \gamma_{G}}\right)$ by itself.

However although figure 4 describes the preferred solution with commitment power over the whole expected office duration, there is no reason to assume that this solution can be enforced, given the assumption that governmental programs are set up for one office term, but not for longer periods. Knowing that there is scope for renegotiation at each date, where a new government enters or is reelected, makes it not credible that the central government could maintain the preferred allocation at periods $(t+2)$ and $(t+3)$ in the staggered regime. Given the lack of credibility, it becomes optimal for the regional government to implement the 


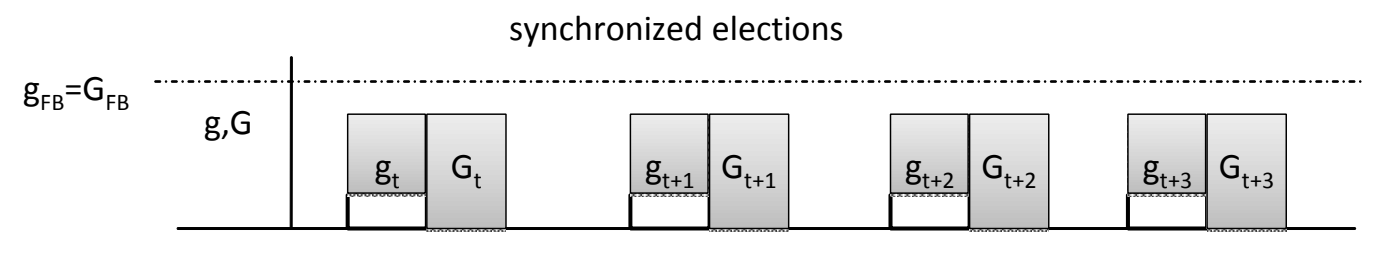

staggered elections

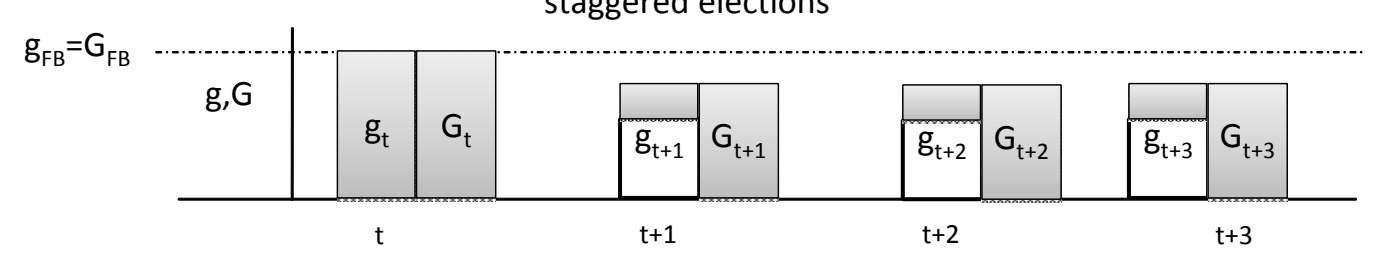

Figure 4: Results with commitment. 
strategic solution $s_{t+2}=0$ for date $(t+2)$. Once the central government enters office at $(t+2)$ and is able to set-up a new program, it will be irresistible to finance all public good provision on its own. This in turn renders it optimal for the regional government to exploit its strategic advantage in the same manner as in the setup with the one-office term restriction, which yields the initial solution for the staggered office term regime.

\subsection{The role of the balanced budget constraint assump- tions}

The possibility to freely shift funds from one period to another within one office term, along with the assumption of a strict budget balancing constraint over the whole office term, seems very strict at first glance. Therefore, we discuss in this section the implications of those assumptions, along with the consequences of their relaxation.

First, we turn the attention to the absence of the intra-office term budget constraint. While the absence of this constraint does not imply an uneven distribution of public funds over time in the synchronized regime, it strongly affects the outcome of the staggered office terms setup. The result that governments alternate over time between financing either a lot or very few of public good provision seems extreme. However, in light of the analysis of political programs, the result has less severe policy implications than it seems at first glance. The broad strategic decisions made in the political program like the general tax policy or expenditure choices, e.g. a reform of the social security system, unfold a binding force over the whole term. Unlike in the model where decisions become binding by taking place chronologically before other decisions, real world political programs are unlikely to allot expenditures unevenly over time periods. In this sense, the result of the staggered office terms regime might be interpreted such that the central government would prefer a larger share of its revenues to be bound in national public programs once it can anticipate the strategic behavior of regional governments. In the same fashion, regional governments might be interested to create a fait accompli with which future central governments have to deal with when setting up their next political programs.

The second potentially controversial part of the budget balancing assumptions is that the budgets need to be balanced at the end of each term of office. One possibility to relax this assumption would be to allow the regional and the central governments to borrow. In the model as it stands, this would lead either to an infinite or to a maximal possible drawing of debt. The reason is that governments do not take into account the utility of public good provision beyond their terms of office. Therefore, any sensible relaxation of the balanced budget constraint over 
the office term should allow governments to take the utility of future payoffs into account. However, once we allow for the consideration of future payoffs, there is no incentive to shift debt into the future as long as governments are equally weighting current and future periods. In an intermediate case where future payoffs are valued by a factor less than one, this would entail indebtedness to some extent. As long as central governments could commit to some optimal level of debt at the beginning of the office term, this would not qualitatively affect our results. However, once central governments were able to raise revenues ex-post at the time they decide on the level of grants, this would destroy the regional governments' incentives to raise any revenues and would lead to full central government financing of regional public goods.

\section{Conclusion}

An interesting result of our analysis is that a staggered office terms regime always increases welfare. This is due to the fact that central government is able to harden budget constraints at least half of the time by spending most of its funds efficiently in the first half of its term of office, where "old" regional governments cannot respond strategically. In the second half of the term only a few funds are left over and the central government prefers to spend these funds for national consumption instead of bailing out sub-national jurisdictions. In the synchronized office terms regime, this commitment effect is absent and soft budget constraints occur in all of the periods.

Our model implies that central governments devote a smaller share of funds to discretionary grants with staggered elections. This result is of particular importance since discretionary grants are sometimes controversial. One policy implication of our analysis is that central governments should take an active role in setting up the electoral timetable for the fiscal discipline of the regional governments as well as the wellbeing of their citizens.

\section{References}

Bergvall, D., Charbit, C., Kraan, D-J, \& Merk, O. 2006. Intergovernmental Transfers and Decentralised Public Spending. OECD Journal of Budgeting, 5, 111159 .

Besfamille, M., \& Lockwood, B. 2008. Bailouts in Federations: Is a Hard Budget Constraint Always Best? International Economic Review, 49(2), 577-593.

Breuillé, M-L., Madiès, T., \& Taugourdeau, E. 2006. Does Tax Competition Soften Regional Budget Constraint? Economics Letters, 90(2), 230-236. 
Crivelli, E., \& Staal, K. 2008. Size, Spillovers and Soft Budget Constraints. Working Paper Series of the Max Planck Institute for Research on Collective Goods, Max Planck Institute for Research on Collective Goods.

Goodspeed, T. 2002. Bailouts in a Federation. International Tax and Public Finance, 9, 409-421.

Hajnal, Z., \& Lewis, P. 2003. Municipal Institutions and Voter Turnout in Local Elections. Urban Affairs Review, 38(5), 645-668.

Joumard, I., Price, R, \& Sutherland, D. 2005. Fiscal Rules for Sub-Central Governments. OECD Economics Department Working Papers No. 465.

Koethenbuerger, M. 2007. Ex-Post Redistribution in a Federation: Implications for Corrective Policy. Journal of Public Economics, 91(3-4), 481-496.

Kornai, J. 1979. Resource-Constrained versus Demand-Constrained Systems. Econometrica, 47(4), 801-819.

Kornai, J. 1980. Economics of Shortage. Amsterdam: North-Holland publishing company.

Kornai, J., Maskin, E., \& Roland, G. 2003. Understanding the Soft Budget Constraint. Journal of Economic Literature, 41(4), 1095-1136.

Qian, Y., \& Roland, G. 1998. Federalism and the Soft Budget Constraint. American Economic Review, 88(5), 1143-1162.

Rodden, J., Eskeland, G. S., \& Litvack, J. 2003. Fiscal Decentralization and the Challenge of Hard Budget Constraints. MIT Press.

Samuels, D. 2004. Presidentialism and Accountability for the Economy in Comparative Perspective. American Political Science Review, 98, No. 3, 425-436.

Shugart, M. 1995. The Electoral Cycle and Institutional Sources of Divided Presidential Government. The American Political Science Review, 89, No. 2, $327-343$.

Vigneault, M. 2007. Grants and Soft Budget Constraints. In: Shah, Anwar, \& Boadway, Robin (eds), Intergovernmental Fiscal Transfers: Principles and Practice. Washington, DC: The World Bank.

Wildasin, D. 1997. Externalities and Bailouts. Hard and Soft Budget Constraints in Intergovernmental Fiscal Relations. Worldbank Policy Research Working Paper, 1843. 


\section{Appendix}

\subsection{Appendix 1 Welfare analysis}

The following table gives the results of the government's tools

\begin{tabular}{|l|l|l|l|}
\hline & SP & SY & ST \\
\hline$g_{t}$ & $\gamma_{g}$ & $\gamma_{g} \frac{\gamma_{g}+\gamma_{G}}{\gamma_{g}+(1+N) \gamma_{G}}$ & $\gamma_{g}$ \\
\hline$g_{t+1}$ & $\gamma_{g}$ & $\gamma_{g} \frac{\gamma_{g}+\gamma_{G}}{\gamma_{g}+(1+N) \gamma_{G}}$ & $\gamma_{g} \frac{\gamma_{g}+\gamma_{G}}{\gamma_{g}+(1+N) \gamma_{G}}$ \\
\hline$G_{t}$ & $(1+N) \gamma_{G}$ & $(1+N) \gamma_{G} \frac{\gamma_{g}+\gamma_{G}}{\gamma_{g}+(1+N) \gamma_{G}}$ & $(1+N) \gamma_{G}$ \\
\hline$G_{t+1}$ & $(1+N) \gamma_{G}$ & $(1+N) \gamma_{G} \frac{\gamma_{g}+\gamma_{G}}{\gamma_{g}+(1+N) \gamma_{G}}$ & $(1+N) \gamma_{G} \frac{\gamma_{g}+\gamma_{G}}{\gamma_{g}+(1+N) \gamma_{G}}$ \\
\hline \multirow{2}{*}{$\tau^{R}$} & $2\left(\gamma_{g}+\gamma_{G}(1+N)\right)$ & $\left(\gamma_{g}+\gamma_{G}\right)-(1+N) \tau^{C}$ & $2\left(\gamma_{g}+\gamma_{G}(1+N)\right)$ \\
& $-(1+N) \tau^{C}$ & $-N \gamma_{G}-(1+N) \tau^{C}$ \\
\hline
\end{tabular}

From the comparison of the results we obtain:

$$
\begin{array}{rlr}
\tau^{R, S P} & >\tau^{R, S T}>\tau^{R, S Y} \\
g_{t}^{S P} & =g_{t}^{S T}>g_{t}^{S Y} & g_{t+1}^{S P}>g_{t+1}^{S T}=g_{t+1}^{S Y} \\
G_{t}^{S P} & =G_{t}^{S T}>G_{t}^{S Y} & G_{t+1}^{S P}>G_{t+1}^{S T}=G_{t+1}^{S Y}
\end{array}
$$

The utilities are given by

$$
U^{S P}=2 w+N \tau^{C}-2\left(\gamma_{g}+(1+N) \gamma_{G}\right)+2 \gamma_{g} \ln \gamma_{g}+2(1+N) \gamma_{G} \ln \gamma_{G}(1+N)
$$

and

$$
\begin{aligned}
U^{S Y}= & 2 w+N \tau^{C}-2\left(\gamma_{g}+\gamma_{G}\right)+2\left(\gamma_{g}+(1+N) \gamma_{G}\right) \ln \frac{\left(\gamma_{g}+\gamma_{G}\right)}{\gamma_{g}+(1+N) \gamma_{G}} \\
& +2 \gamma_{g} \ln \gamma_{g}+2 \gamma_{G}(1+N) \ln (1+N) \gamma_{G}
\end{aligned}
$$

and

$$
\begin{aligned}
U^{S T}= & 2 w+N \tau^{C}+2 \gamma_{g} \ln \gamma_{g}+2(1+N) \gamma_{G} \ln (1+N) \gamma_{G}-\left(\gamma_{g}+\gamma_{G}\right) \\
& -\left((1+N) \gamma_{G}+\gamma_{g}\right)+\left(\gamma_{g}+(1+N) \gamma_{G}\right) \ln \frac{\left(\gamma_{g}+\gamma_{G}\right)}{\gamma_{g}+(1+N) \gamma_{G}}
\end{aligned}
$$


The difference between the ST welfare function and the SY welfare function is given by

$$
U^{S Y}-U^{S T}=\left(\gamma_{g}+(1+N) \gamma_{G}\right)\left(\ln \frac{\left(\gamma_{g}+\gamma_{G}\right)}{\gamma_{g}+(1+N) \gamma_{G}}+1-\frac{\left(\gamma_{g}+\gamma_{G}\right)}{\left(\gamma_{g}+(1+N) \gamma_{G}\right)}\right)<0
$$

since if we set $x=\frac{\left(\gamma_{g}+\gamma_{G}\right)}{\gamma_{g}+(1+N) \gamma_{G}}$ the function $f(x)=1-x+\ln x<0 \forall x$

and

$$
\begin{aligned}
U^{S P}-U^{S T} & =-\left(\gamma_{g}+(1+N) \gamma_{G}\right)+\left(\gamma_{g}+\gamma_{G}\right)-\left(\left(\gamma_{g}+(1+N) \gamma_{G}\right) \ln \frac{\left(\gamma_{g}+\gamma_{G}\right)}{\left(\gamma_{g}+(1+N) \gamma_{G}\right)}\right) \\
& =\left(\gamma_{g}+(1+N) \gamma_{G}\right)\left(-1+\frac{\gamma_{g}+\gamma_{G}}{\gamma_{g}+(1+N) \gamma_{G}}-\ln \frac{\left(\gamma_{g}+\gamma_{G}\right)}{\left(\gamma_{g}+(1+N) \gamma_{G}\right)}\right)>0
\end{aligned}
$$

then

$$
U^{S P}>U^{S T}>U^{S Y}
$$

